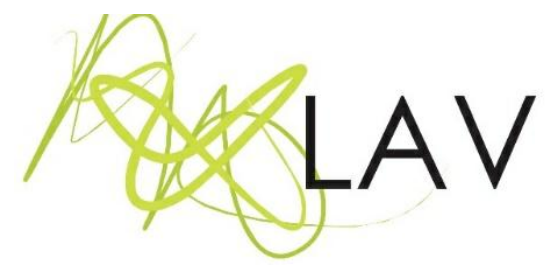

\title{
Mergulho netnográfico nas narrativas surdas: conversações com as imagens fenômenos
}

A netnographic delving into the deaf people narratives: conversations with the phenomena images

Welliton Quaresma de Limai Universidade Federal do Amapá

Silvia Carla Marques Costaii Universidade Federal do Amapá

\section{Resumo}

O presente artigo é constituído por recortes de viagens investigativas realizadas no campo dos estudos da Cultura, Identidade e Linguagem. O método utilizado para construção dos dados foi a Netnografia, meio de navegação pelos vastos e complexos mares das redes sociais de algumas pessoas surdas, a fim de buscar compreender os processos de socialidade e constituição das subjetividades desses sujeitos e de suas culturas. Partiu-se da compreensão das potencialidades das imagens para a construção de conversações, reflexões e interpretações das realidades das vivências surdas. As imagens foram entendidas aqui não como mero suporte pictórico para apreciação, mas como fenômenos polissêmicos participantes dos processos de construção de sentidos sociais e das identidades.

Palavras-chave: netnografia, surdos, imagem.

\section{Abstract}

This article consists of clippings of investigative trips carried out in the field of Culture, Identity and Language studies. The method used to construct the data was Netnography, in which I found routes to navigate the vast and deeply complex seas of the social networks of a group of deaf people, in order to seek understanding the processes of sociality and the constitution of the subjectivities of the participants and their cultures. It started with the understanding of the potentialities of images in building conversations, reflections and interpretations of the realities of deaf experiences. The images were understood here not as a mere pictorial support for appreciation, but as polysemic phenomena participating in the processes of construction of social meanings and identities.

Keywords: netnography, deaf, images. 


\section{Breves recortes de viagens investigativas}

O presente artigo é composto por recortes de minhas viagens investigativas realizadas no Curso de Especialização em Estudos Culturais e Políticas Públicas (PCULT), ofertado pela Universidade Federal do Amapá, seguindo a linha de pesquisa Cultura, Identidade e Linguagem, na qual encontrei rotas para navegar pelos vastos e complexos mares das socialidades e subjetividades dos sujeitos. Para tanto, passei a ver, pensar e sentir narrativas existenciais a partir das imagens, tendo como colaboradores sujeitos surdos que são constituídos de uma diferença, pela qual sou insaciavelmente curioso e interessado em compreender.

Sendo eu ouvinte, adianto-me a esclarecer as possíveis interrogações dos motivos de meu interesse por esse tema de pesquisa. Até mesmo para explicar a escolha metodológica e definição do objeto e campo, acredito ser necessário compartilhar brevemente alguns relatos pessoais que foram propulsores para o desejo de desenvolvimento deste trabalho e reflexões que dele sucedem.

Esta narrativa inicia com as minhas primeiras vivências acadêmicas em 2013, quando adentrei na graduação em Artes Visuais na Universidade Federal do Amapá. Passada a conhecida 'semana do calouro', e partindo para os primeiros dias de aula, notei no momento de socialização das trajetórias de vida de cada aluno da turma, a presença de um colega que, na sua vez de se apresentar, sinalizou que era surdo.

Até então eu não havia percebido a sua diferença, e logo me suscitou o desejo de conhecê-lo com mais profundidade, pois eu havia tido algumas poucas aulas de LIBRAS meses antes. Notei que nem os demais colegas de turma, e nem os professores tinham conhecimento da Língua de Sinais, então me esforcei para tentar repassar algumas informações para o colega surdo, tendo em vista que ainda não haviam encaminhado um intérprete para acompanhá-lo.

Através dos poucos sinais que eu conhecia e de mensagens de textos escritas no celular, aproximei-me das singularidades dos sujeitos surdos. Durante todo o período de quatro anos de graduação, estreitamos a relação de amizade e consequentemente o desejo de compreender como se desenvolviam as relações sociais desse grupo específico (surdos) numa sociedade majoritariamente ouvinte.

Tocado pelas questões observadas na nossa convivência diária na academia, a exemplo dos abismos linguísticos que dificultavam as interações entre ouvintes e surdos num processo de inclusão - configurando-se mais como inclusão do corpo presente do que 
uma inclusão nos processos de socialidades; do despreparo tanto dos docentes como dos discentes para desenvolver relações interpessoais com o colega surdo; do déficit na estrutura da instituição e na adaptação metodológica para o atendimento ao sujeito surdo na academia que acarretavam na reprodução de estigmas, mesmo que muitas vezes de forma involuntária e inconsciente, pela maioria ouvinte.

Saltou-me aos olhos também a facilitação dos diálogos e interações por meio das redes virtuais de comunicação compartilhadas pela turma, por onde conseguimos manter maior interação com o colega surdo, por meio de imagens, vídeos e textos. A aproximação com ele me conduziu ao desenvolvimento do tema de Trabalho de Conclusão de Curso, no qual desenvolvemos juntos uma pesquisa de campo construída por narrativas visuais e reflexões acerca das redes de comunicação dos surdos no contexto escolar.

Na ocasião, estudamos por alguns meses entre 2016 e 2017, as vivências de um grupo de 12 alunos surdos estudantes do Ensino Médio de uma escola da capital de Macapá. No decorrer das observações dos trânsitos desses alunos pelos espaços da escola, atentamos para a reprodução de questões similares às vivenciadas por nós na academia, bem como o forte envolvimento das tecnologias na mediação de troca das informações entre eles.

A partir desse fato, tecemos reflexões pertinentes aos processos de construção de diálogo e relações sociais, em que as línguas maternas de ambos, surdos e ouvintes, eram colocadas em segundo plano, e as imagens assumiam papel singular na construção das socialidades. Naquele contexto, a apropriação das imagens pelos surdos, diante das barreiras linguísticas, contribuiu para refletirmos os deslocamentos dos sujeitos para além das limitações comunicacionais da língua.

Pudemos perceber que, em algumas situações, a comunicação entre surdos, professores e colegas se tornava limitada por estes não possuírem domínio de LIBRAS (Língua Brasileira de Sinais), mesmo diante da inclusão e acessibilidade linguística dos intérpretes, sobretudo quando estes não estavam presentes. Observamos que essa barreira comunicacional reverberava diretamente em suas participações no processo de ensino-aprendizado.

Diante da percepção dessas dificuldades dos alunos surdos em relação à interação e assimilação dos conteúdos oficiais, fomos instigados a pensar em caminhos que ampliassem as possibilidades das experiências entre surdos e ouvintes. Nesse sentido, notamos que fora do recinto das salas de aula, os alunos surdos e ouvintes vivenciavam outras relações de socialidades, pelas quais conexões estéticas alternativas 
potencializavam a autonomia para construírem suas relações e comunicações, tornando dispensável a presença de um intérprete.

Notamos que as imagens compartilhadas nas redes virtuais proporcionam a construção de pontes por onde surdos e ouvintes podem atravessar. Por meio das imagens, as barreiras dos códigos das línguas eram aparentemente superadas e transpassadas pela construção de outros sentidos, outras relações com o mundo. No entanto, essas imagens não serviam apenas para ilustrar, porque elas comunicavam ecos das subjetividades e revelavam nuances das feituras das identidades dos sujeitos.

Tendo vivenciado essas experiências, desenvolvi este estudo compartilhado aqui em breves recortes, em que busco caminhar por vias reflexivas que contornam os diversos estudos já produzidos a respeito do fator linguagem e da LIBRAS na construção das culturas e identidades dos surdos, e me aproximei muito mais do campo das experiências visuais e da produção de imagens por perceber nelas grande potencialidade reflexiva e interpretativa das narrativas existenciais surdas.

A Língua de Sinais, um dos principais meios da subjetividade surda, "é transmitida nas comunidades surdas e, apesar de por muito tempo na história dos surdos ter sofrido a repressão exercida pelo oralismo, a língua de sinais não foi extinta e continuou a ser transmitida, de geração em geração, pelo povo ${ }^{1}$ surdo com muita força e garra" (STROBEL, 2015 , p. 46). Apesar de ter consciência disso, o enfoque dado neste trabalho é para outras questões reflexivas.

Por isso, a escolha de rumar o trabalho pelo viés da pesquisa qualitativa se faz por conta de sua ampla possibilidade investigativa das subjetividades dos sujeitos, na qual me embasei para pensar os trânsitos dos interlocutores como construtores autônomos de experiências existenciais/visuais projetadas nas redes de socialidade/sociabilidade ${ }^{2}$ virtual. Entendendo que os sujeitos surdos se apropriam de imagens como principal via de acesso ao mundo, pelas quais se constroem como ser social e historicamente situado.

\footnotetext{
${ }^{1}$ É importante ressaltar que "[o] povo surdo não é em si um fim acabado, pronto. [...] Não há entre os surdos um consenso comum quanto ao povo. Uns enfatizam o aspecto de comunidade, outros de associação, outros ainda de grupo, ou de luta. Alguns se referem a esta diferença pela língua de sinais, outros como minoria, como grupo subalterno" (PERLIN, 2003, p. 113).

${ }_{2}$ Apropriei-me do conceito de socialidades neste estudo, por perceber maior alargamento dos caminhos para se chegar às dimensões em que os atores sociais constroem subjetividades, em que forjam identidades, pois "[a]s socialidades seriam uma maneira de imaginar a existência numa "conjugação de sensibilidades", na multiplicação das redes e grupos sociais que se constituem. Olhar para esta perspectiva é se concentrar nas experiências singulares" (SILVA, C. 2009, p. 47).
}

Revista Digital do LAV - Santa Maria - vol. 14, n. 1, p. 138 - 158 - jan./abr. 2021 ISSN 1983 - 7348 http://dx.doi.org/10.5902/1983734847834 
Embebido na percepção da forte conectividade tecnológica e da produção e compartilhamento de imagens nos processos entrelaçados de construção das identidades dos sujeitos surdos na contemporaneidade, escolhi enveredar pelos caminhos da netnografia, pois essa metodologia se mostrou como uma potente ferramenta investigativa para um mergulho observacional e interpretativo das subjetivas realidades que se constituem nos novos territórios existenciais do mundo social digital. Kozinets (2014) afirma que o mundo digital "transformou radicalmente as ideias das pessoas sobre com quem, quando, como, com que frequência e até por que elas podiam se comunicar" (KOZINETS, 2014, p. 69).

As possibilidades metodológicas da Netnografia se mostraram amplamente pertinentes para compreensão das realidades a partir de um olhar sensível para as idiossincrasias dos sujeitos. Kozinets (2014) salienta que essa ferramenta pode ajudar a "investigar os significados por trás das relações e vínculos"; potencializar compreensões de questões como "por que' para uma série de características, tais como relações de poder e influência, vários tipos de vínculos sociais, e as aglomerações de subgrupos e panelinhas" (KOZINETS, 2014, p. 56).

Além disso, o autor afirma que:

[d]e modo semelhante, a análise de redes sociais e suas ricas técnicas de visualização podem elucidar, alargar e fornecer ideias e evidências adicionais que ajudem a revelar as propriedades e as relações que constituem o complexo mundo das comunidades e culturas online (KOZINETS, 2014, p. 56).

Por conta disso, apropriei-me dessa ferramenta e por ela fui ao encontro dos meus interlocutores, buscando, nas janelas e abas abertas num clique, possibilidades de transpor a barreira da língua e também da linha do tempo e construir dados a partir de informações postadas em múltiplos recortes temporais, acompanhar os sujeitos de qualquer região geográfica, realizar contatos síncronos e assíncronos. Essas são algumas das vantagens da netnografia em contraste com outros métodos, como a etnografia clássica, e por isso dela lanço mão. Nas palavras de Kozinets (2014):

[...] a netnografia pode proporcionar ao pesquisador uma janela para comportamentos que ocorrem naturalmente, tais como discussões comunais, e depois realçar tal compreensão com opções mais intrusivas, tais como participação comunal e entrevistas com membros. Os etnógrafos em pessoa não têm a opção de espreitar invisivelmente, ou a possibilidade de recuar no tempo para rastrear com perfeição conversas comunais (KOZINETS, 2014, p. 58). 
Seguindo essa proposta, coloquei-me à espreita do campo para observação dos trânsitos de sujeitos surdos em algumas das principais redes de comunicação virtual na atualidade, nas quais surfei em busca de compreender os processos de construções identitárias nos intercâmbios de imagens.

Nesta ação investigativa virtual, meu grande aliado foi o aparelho celular que, devido a sua fácil mobilidade, múltiplas funcionalidades, possibilitadores de encontros, torna-se, "em certa medida, um novo instrumento que é adicionado à caixa de ferramentas do investigador" (LA ROCCA, 2014, p. 120). Sobre isso, o autor também comenta:

A conectividade tecnológica será um sintoma da construção das identidades sociais e o fluxo de imagens, um entrelaçamento dinâmico para referir-se a diversos territórios existenciais do mundo social e também ao habitat digital que é a tela. Um habitat como espaço eco-simbólico, onde a produção de imagens dá nascimento a um museu imaginário que evoca lugares, territórios, momentos da vida quotidiana e cria memórias e emoções (LA ROCCA, 2014, p. 123).

O aporte teórico investido por mim para interpretação das realidades observadas transitou pelos Estudos Culturais, Estudos Surdos, Cultura Visual, Pós-colonialismo, a fim de lançar mão de prismas que proporcionaram o vislumbrar dos espectros das múltiplas cores que compõem as redes de sentido existencial/identitário de indivíduos subalternizados ao longo da história.

Assim, tomado por um olhar curioso, sensível, deixei-me envolver nas tramas virtuais de comunicação de um grupo de jovens surdos usuários das redes sociais Facebook, Instagram e do WhatsApp, observando as narrativas forjadas nos emaranhados de informações, imagens, vídeos, textos, links, que deslizam autônoma e freneticamente nas redes de interação virtual, transpondo barreiras comunicacionais através da apropriação polissêmica de imagens.

A partir das interlocuções com as imagens, busquei compreender as realidades de sujeitos que explicitam em suas ações virtuais a não existência de essencialidade surda e lutam pela desconstrução de narrativas estigmáticas impostas historicamente por uma concepção patológica que os imputa a marca de deficientes.

Em tempos onde as estruturas das identidades são compreendidas como constructos sociais fluidos, hibridizadas, entrecruzadas por diversas culturas do globo terrestre, abrem-se caminhos para o surgimento de diversas outras manifestações 
identitárias e potencialmente outras formas flexíveis de compreensão e interpretação dos universos surdos.

Meu interesse nesta investigação foi buscar compreender como têm sido constituídas as subjetividades identitárias de sete surdos, num cenário de transformações contínuas e frenéticas, articuladas fortemente pelos artefatos eletrônicos, mídias visuais e as múltiplas experiências produzidas por esses novos territórios de vivência social e constituição de sujeitos.

O intuito foi problematizar como o consumo e produção de imagens participam no forjamento identitário de sujeitos da experiência visual ${ }^{3}$. Desnaturalizando saberes, poderes, essencialidades que envolvem as representações das formas de ser sujeito surdo no cenário atual.

Os pensamentos confluem nos eixos temáticos das questões de identidades, imagem e surdez, em que construo diálogos com teóricos de distintos eixos das ciências sociais que se debruçam a pensar as complexas transformações vivenciadas pelas hodiernas sociedades humanas, tendo como recorte principal as vivências surdas.

Por intermédio de um mergulho netnográfico, os sentidos e encontros visuais foram propulsores para a definição dos sujeitos da pesquisa e do campo a ser explorado. Buscouse observar os caminhos percorridos por alguns surdos nas redes sociais Instagram e Facebook.

Relato as vivências oportunizadas pela pesquisa qualitativa, na qual lancei mão das ferramentas investigativas da netnografia para me aproximar do grupo de surdos que também foram colaboradores na pesquisa realizada anteriormente. Os sujeitos dessa pesquisa são sete jovens estudantes do sexo feminino e masculino, na faixa etária de 18 a 28 anos.

Entendendo que as redes sociais se constituem como espaços de possibilidades para os estabelecimentos de conexões, busquei explorar relações, interações, comunicações flexíveis, abrindo janelas ${ }^{4}$ para o acesso às cenas das subjetividades, existencialidades

\footnotetext{
${ }^{3}$ A expressão 'sujeitos da experiência visual' descreve sujeitos que na área de minha formação, a Educação Especial, foram e são tratados como deficientes: os surdos. Esses sujeitos são discursivamente constituídos por meio de instâncias culturais da contemporaneidade, que são mais do que simples expressões culturais, são artefatos que circulam nas culturas, que vão ensinando esses sujeitos e subjetivando-os (BATAGLIN, 2012, p. 01).

${ }^{4} \mathrm{~A}$ imagem da janela como portal de acesso às subjetividades dos sujeitos é abordada por La Rocca (2011, p. 52) que compreende a janela como "um símbolo de mediação entre indivíduos e o espaço, colocando-o como espectador da cena urbana; uma espécie de espelho no qual se refletem as existências quotidianas e os diversos signos que acompanham os nossos percursos".
} 
quotidianas, saberes dos sujeitos por meio de imagens criadas pelos próprios navegantes. Além disso, busquei compreender esses fenômenos a partir de leituras que conduzem à compreensão dessas imagens, não como mero suporte pictórico para apreciação, mas como fenômenos polissêmicos participantes dos processos de construção de sentidos sociais e das identidades.

Ressalto o entendimento que os imbricamentos imagéticos e identitários, potencializados pela abundante produção e circulação de imagens pelas mídias visuais, transformaram e continuam a transformar, potencialmente, nossas formas de construir socialidades e forjar as narrativas e as tramas sociais.

Procurei entender como os indivíduos surdos têm se apropriado das imagens expostas em suas redes sociais na construção de suas identidades, subjetividades, visualidades, poéticas de vida, dando outros sentidos para o que/como se vê, o que/como se comunica por/com imagens, para além do aparente e figurativo, a partir dos seguintes questionamentos: Quais os sentidos empregados nas produções dos indivíduos que se comunicam com o mundo pelo campo da percepção visual? O que desejam comunicar? Como são produzidas as experiências estéticas dos surdos a partir de imagens? Como as identidades são forjadas nesse processo de socialidade amplamente virtualizado?

As questões abordadas transcorrem o enfoque conceitual do que seriam as identidades? Como elas se constituem? Pensando concomitantemente a participação nesses processos das imagens fenômenos, manifestas nas vivências cotidianas de surdos contemporâneos, entendendo as identidades pela via socioantropológica, como não essenciais, fixas, mas como campo de constante disputa de poder, como fenômenos sociais. Problematizei também quais os padrões de comportamento, novas referências identitárias, transmutações que emergem nos campos virtuais, como afetam o panorama de constantes transformações, em especial nas redes de sentidos dos sujeitos surdos.

Nessa aproximação com os estudos do universo surdo fazendo conexões com os Estudos Culturais, resgatei fatos de vivências estigmáticas históricas, sociais e culturais imputadas aos surdos por um pensamento ouvintista pautado num discurso clínico que reverbera até os dias atuais nas formas como são construídas as visualidades sobre os sujeitos da experiência visual.

Para melhor nortear como compreendo aqui o 'Ser Surdo', recordo o conceito desenvolvido por Eiji (2012). Para o autor, a experiência da surdez é percebida "como um modo de existir, como outros vários", sendo que, nesse modo singular, os sujeitos têm as 
suas vivências, socialidades e narrativas de vida fundadas "na experiência visual e no uso das línguas de modalidade viso-motora (as línguas gestuais) - e legitima-se mais como um atributo cultural construído historicamente que como uma experiência unívoca e inexorável de um corpo mutilado" (EIJI, 2012, p. 3).

Nesta pesquisa, problematizo essas experiências visuais dos sujeitos surdos enquanto minoria subalternizada numa sociedade majoritariamente ouvinte, evidenciando a partir das observações netnográficas os trânsitos virtuais de um grupo de sete sujeitos surdos e os tensionamentos que eles produzem na abertura de outros horizontes para se pensar a experiência da surdez. Dessa forma, procuro entender como tem sido produzidas as subjetividades desses interlocutores num contexto mundial de profundos deslocamentos de sentidos e estruturas identitárias.

Algumas costuras analíticas foram realizadas a partir dos tecidos das experiências dos encontros visuais com os sujeitos surdos. Apresento algumas das imagens registradas nas observações netnográficas e algumas interlocuções visuais que percebi no fazer inventivo da vivência surda nas redes sociais.

Ao final do processo de observação, o meu arquivo de imagens registradas era de aproximadamente 250 imagens que me seduziram e conduziram a repensar construções de visualidades que estava acostumado sobre os surdos. Dei a mim permissão poética, das quais os artistas, etnógrafos, netnógrafos se apropriam, para nomear as imagens e delas fazer as categorias de minhas análises para discutir a imagem.

As categorias analíticas oriundas da compreensão das imagens são para mim suas referências identitárias e da produção de sentidos. Stuart Hall (2006) que me ajudou a delinear qual seria a compreensão de identidade no decorrer da história e como esse conceito chega a nós na contemporaneidade.

As identidades são fenômenos sociais que sofrem mutações de acordo com as demarcações relacionais e subjetivas no espaço e tempo. Uma evidência dessa proposição é a de que "[...] as velhas identidades, que por tanto tempo estabilizaram o mundo social estão em declínio, fazendo surgir novas identidades e fragmentando o indivíduo moderno, até aqui visto como um sujeito unificado" (HALL, 2006, p. 7).

Não intento com essas interpretações apontar verdades, nem enquadrar o que seja a identidade de outrem, tão somente compartilhar algumas compreensões a partir de alguns eixos reflexivos, nos quais evidenciei algumas categorias de análise percebidas nas 
interlocuções das imagens, construindo bricolagens com minhas interpretações e contribuições dos autores dos textos lidos.

Compreendi nesta empreitada investigativa que a imagem produz polifonias que ecoam de diferentes formas, as quais chegaram como um convite para observar a existência de corpos inventivos que experimentam o mundo por outros canais sensíveis, "ou seja, suas experiências são baseadas pelo visual, e não pelo auditivo como a maioria esmagadora da sociedade amapaense, brasileira e mundial" (CAMPOS, 2016, p. 52).

Seduzido pelas múltiplas construções de imagens, intentei ir além da imagem em si, observando os trânsitos de sentidos dos participantes de uma cultura viva, pulsante, que se (re)produz nas potencialidades de corpos autônomos, fluidos, que se movimentam por meio de outras sensações, afetos e percepções, criando uma forma de ser própria, e que através da imagem materializa forças que os atravessam.

\section{Entre o visível e o invisível das imagens: considerações dos horizontes possíveis das formas de ser surdo}

A ideia de comunicação de sentidos existenciais por meio das imagens, muito me excita, e este tema para mim é insaciável, por isso empreendi pesquisá-lo, buscando por novos horizontes reflexivos das formas possíveis de dialogias imagéticas das transformações do ser surdo nos dias atuais. As imagens se apresentam como expressão de comunicação do invisível a partir de bricolagens simbólicas que transpassam as redes de sentidos construídos na experimentação da vida.

Neste exercício investigativo, busquei problematizar as invisibilidades das narrativas existenciais, subjetivações dos sujeitos surdos, potencialidades das singularidades dos indivíduos nas práticas cotidianas, tendo como interlocutores as visibilidades das imagens compartilhadas cotidianamente por meus interlocutores nas suas redes sociais. 


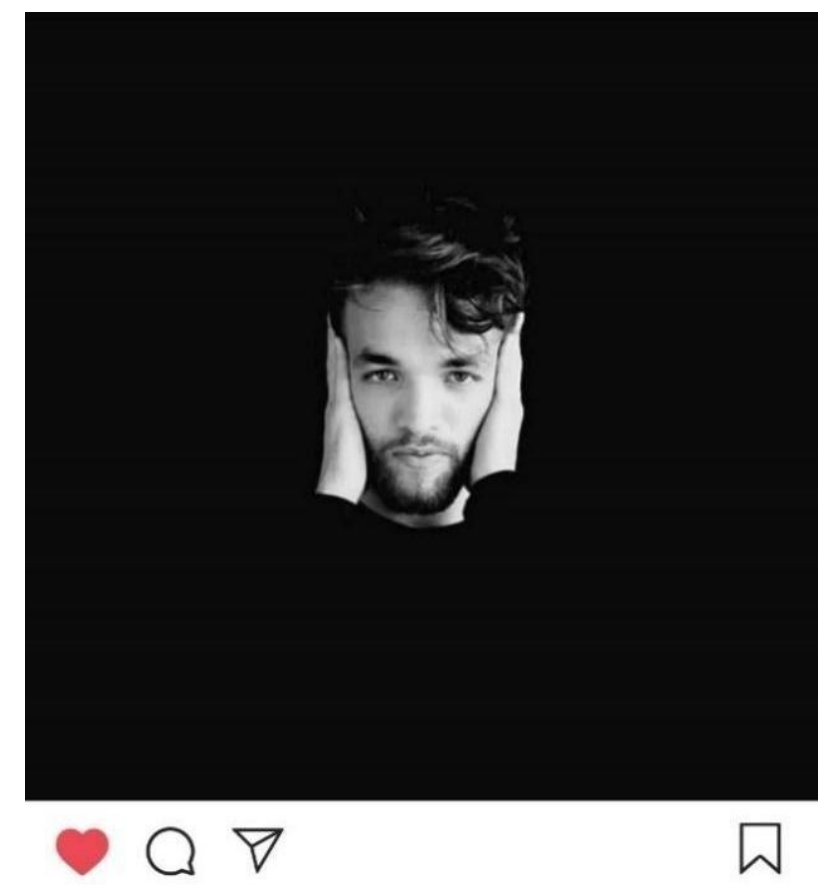

Figura 1: Intensidades

Fonte: Print Screen elaborado pelo autor (2018)

Como podemos analisar na figura 1, intitulada Intensidades, os surdos além de se apropriarem e utilizarem um espaço alternativo de socialidade, como o Instagram, para expressar e construir as intensidades seus referenciais identitários coletivos e individuais; tecer redes de sentidos e pertencimento étnicos; comunicar-se com o mundo e suas diversas culturas, evidenciavam também as lutas do povo surdo por meio de postagens políticas que evocavam tensões pela descolonização do olhar sobre os corpos surdos, contestando e desconstruindo lógicas de um pensamento ouvintista.

Tentei compreender sinalizações de como as imagens participam dos processos de construção/transformação das referências identitárias dos surdos contemporâneos, tendo como campo as redes sociais para o desenvolvimento da pesquisa, e as imagens como interlocutores produzidas por surdos.

As perspectivas dos Estudos Culturais corroboraram para que eu pudesse realizar esse mergulho reflexivo e observacional nas movimentações desse grupo social subalternizado ao longo da história. O conceito de cultura aqui apropriado foi o compartilhado pelos teóricos dessa área de estudo, os quais entendem que "a cultura não é um campo autônomo nem externamente determinado, mas um local de diferenças e de lutas sociais" (SILVA, 2006, p. 13), um local onde jogos de poder são travados pela significação social. 


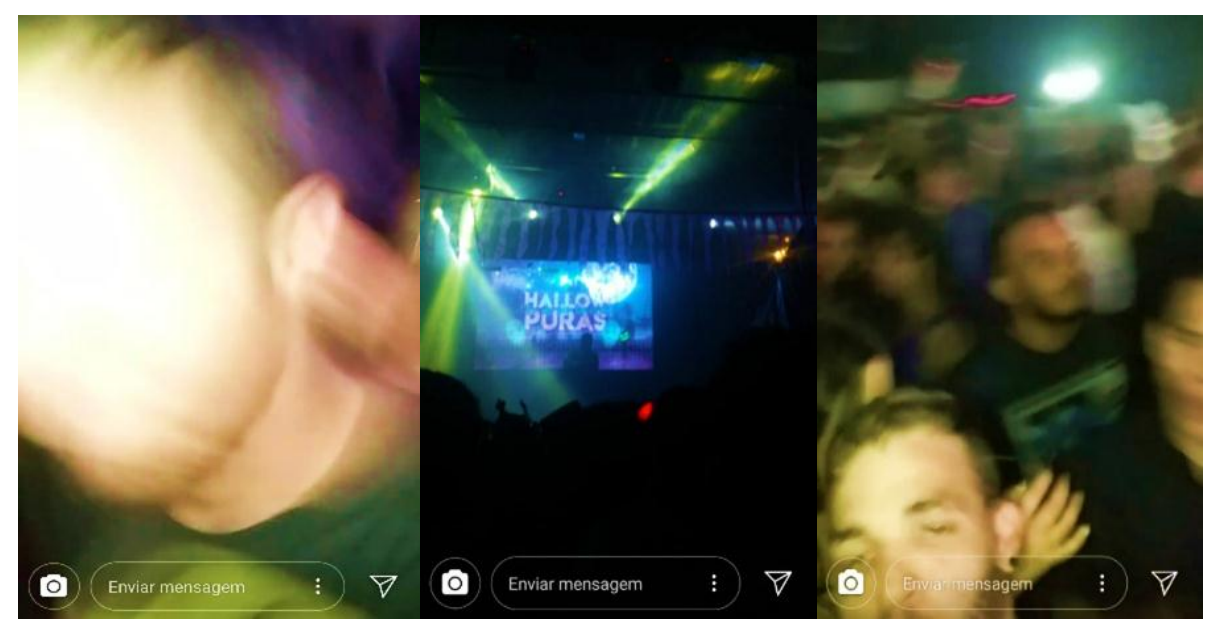

Figura 2: Deslocamentos de sentidos Fonte: Print screen feito pelo autor (2018)

A partir do mergulho observacional netnográfico, costurei narrativas de interpretações dos sentidos existenciais, referências identitárias que plasmavam em suas imagens postadas nas redes sociais. Percebi que, no espaço virtual, os surdos constroem novas possibilidades de experiências intensas, deslocamentos de sentidos, salientam subjetividades individuais e coletivas. Ademais, nutrem práticas políticas de reivindicação da singularidade surda, desaguando em embates pela emancipação surda das perspectivas dominantes e estigmatizantes, como na figura 3 :

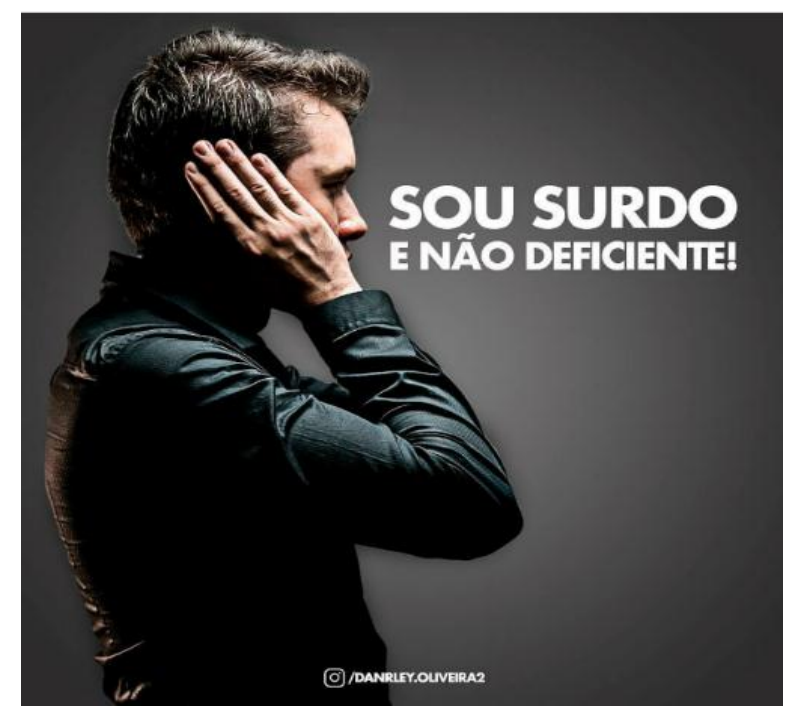

Figura 3: Ser surdo

Fonte: Print Screen elaborado pelo autor (2019)

Ao atinar para a apropriação das redes virtuais de interação pelos sujeitos surdos, busquei construir conversações com as polifonias e pegadas simbólicas que eclodiam nas imagens compartilhadas pelos colaboradores da pesquisa. Nesse novo campo de vivências,

Revista Digital do LAV - Santa Maria - vol. 14, n. 1, p. 138 - 158 - jan./abr. 2021 ISSN 1983 - 7348 http://dx.doi.org/10.5902/1983734847834 
surdos e ouvintes, transitavam autonomamente, conferindo um ambiente de comunicabilidade ampliada, uma ponte para os abismos das linguagens.

Percebi que nesses processos de constantes amoldamentos as tecnologias e artefatos visuais são tomados pela necessidade de comunicabilidade humana e possibilitavam o transpor das barreiras comunicacionais observadas nas interações pelo uso das línguas, pois, como recorda Kozinets (2014, p. 71), "falantes do mandarim tendem a permanecer como falantes do mandarim, e raramente participam de conversas com falantes de húngaro e português".

Nesse sentido, diante das barreiras naturais das línguas, no caso dos sujeitos surdos percebe-se que há outra dimensão dessa dificuldade, pois a comunicação fica embarreirada com qualquer outra língua oral-auditiva, por ser a Língua de Sinais, uma estrutura de outra dimensão sensível, apropriada por outro canal, o visual. Foi diante dessa percepção que busquei explorar a potência da apropriação polissêmica de imagens nas comunicações e interações surdas nas redes virtuais e como os sujeitos surdos construíam suas experiências visuais, subjetivas, identitárias e socioculturais.

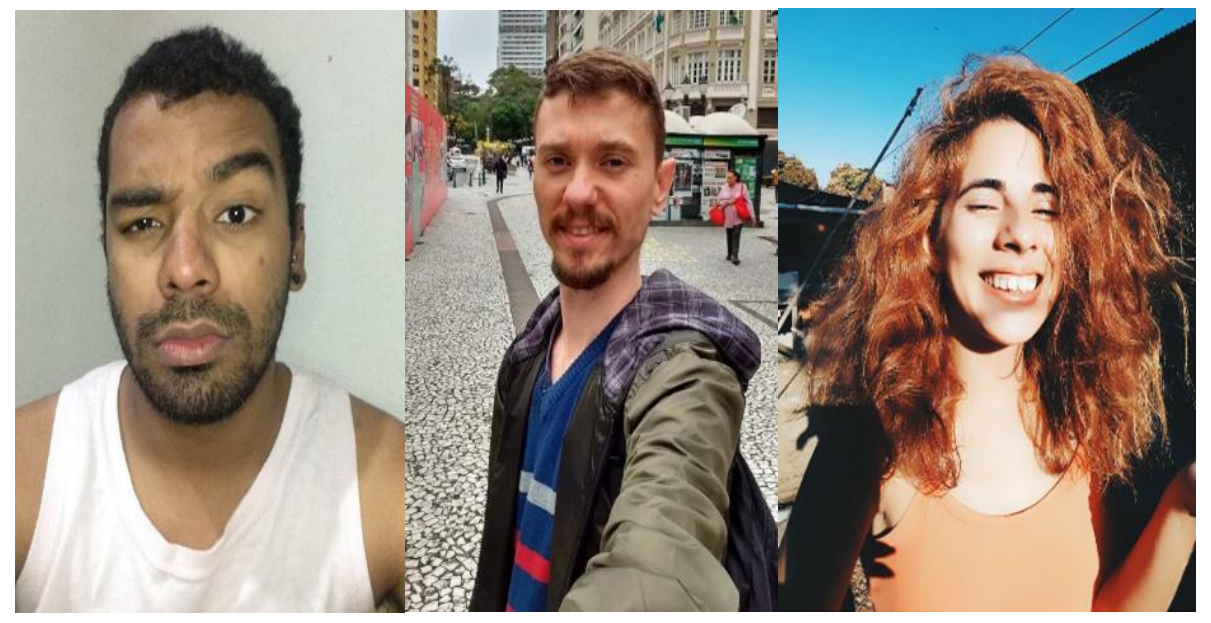

Figura 4: Narrativas existenciais 1

Fonte: Print screen elaborado pelo autor (2018)

Há nos dias atuais uma grande facilidade de produção e disseminação das imagens que se comportam não somente como registro pictórico temporal, mas como participante dos processos de produção de alteridades, memórias, produzem sentimentos, provocam tensão social, pois "usar palavras e imagens é agir: graças a elas, podemos criar universos e com elas construímos nossas subjetividades, nutrindo o mundo com um rico acervo de significações" (SIBILIA, 2008, p. 31). 
Buscando possibilidades de me embrenhar nas suas vivências, nos seus trânsitos comunicativos, pensei a partir das imagens, compreendidas como "poços de humanidade" (SAMAIN, 2012). Dialoguei com as diversas vozes das imagens compreendendo-as como fenômenos sociais, posto que elas "articulam e se oferecem como encontros flexíveis de mediação e comunicação" (MARQUES, 2017, p. 98), possibilitando e evidenciando com isso as realidades dos sujeitos.

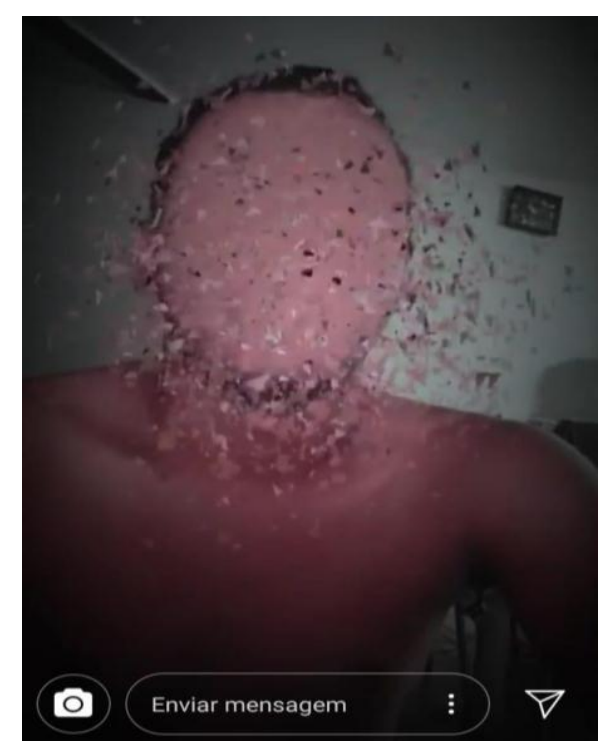

Figura 5: Indeterminado

Fonte: Print screen elaborado pelo autor (2018)

Compreendi e interpretei as imagens como seres pensantes que falam, insinuam, apresentam, descortinam humanidades, realidades sociais e subjetividades. Elas permitem adentrar em múltiplas camadas de sentidos das narrativas de identidades indeterminadas que nem sempre é possível pela linguagem escrita, e instigam outras reflexões, sensações, interpretações. Essas imagens revelam as indeterminações das identidades que se constituem por fragmentos, pulverizações de experiências e sentidos.

Como recorda Samain (2012, p. 14), as imagens são "portadoras de pensamentos e como tal nos fazem pensar". Ainda, segundo esse autor, provoca-se a compreensão de que "as imagens pertencem à ordem das coisas vivas, ao mesmo título que os problemas de beleza, os caranguejos do mar, as orquídeas e os seres humanos" (SAMAIN, 2012 p. 157).

Norteado por esse prisma epistemológico me ative a perseguir as imagens, comuniquei-me com esses seres vivos, imagens fenômenos que me ajudaram a tentar 
compreender as subjetivas tramas de vida, narrativas coletivas e individuais dos sujeitos surdos que socializavam nas redes virtuais.

Se admitirmos, deste modo, que toda imagem pertence à grande família dos fenômenos, não poderemos mais equiparar uma imagem a uma bola de sinuca ou a um prego que a tábua engole quando, nela, o martelo bate. Sem chegar a ser um sujeito, a imagem é muito mais que um objeto: ela é o lugar de um processo vivo, ela participa de um sistema de pensamento. A imagem é pensante (SAMAIN, 2012, p. 158).

Concordando com Samain (2012), diante desses processos vivos, pude notar as transitoriedades dos corpos, das identidades, dos sentidos, dos desejos e das alteridades construídas pelos interlocutores que, além de produzirem imagens, provocam um pensamento acerca da cultura surda. Além disso, qualificam suas existências em eclosões imagéticas carregadas de significações nos complexos e contínuos fluxos existenciais, contrapondo imagens que os colocavam na posição de subalternidade.

Strobel (2015) comenta sobre o significado de cultura surda, que se constitui não hegemonicamente, mas partindo do eixo da experiência visual como campo para produção de múltiplos sentidos:

Cultura surda é o jeito de o sujeito surdo entender o mundo e de modificá-lo a fim de torná-lo acessível e habitável, ajustando-o com as suas percepções visuais, que contribuem para a definição das identidades surdas e das "almas" das comunidades surdas (STROBEL, 2015, p. 22).

Nesse horizonte, dialoguei com autores que compreendem os sujeitos surdos e suas comunidades como produtores ativos de uma cultura viva, que se manifesta atrás de artefatos primariamente visuais. Problematizam a construção histórica de estereótipos baseados num discurso clínico do surdo, como sujeito deficiente, frágil, neutro, limitado, pobre coitado, incapaz. Desconstruir essas visualidades, os colaboradores da pesquisa apresentaram-se, a partir das imagens compartilhadas em ambiente, como o Facebook, como seres em construção, transitantes, inventores de suas próprias identidades e sentidos de vida, que desejam, sonham, provocam reflexões, problematizam os estereótipos imputados, reivindicam seus espaços e direitos, tornando-se participantes ativos dos jogos de poder social. 


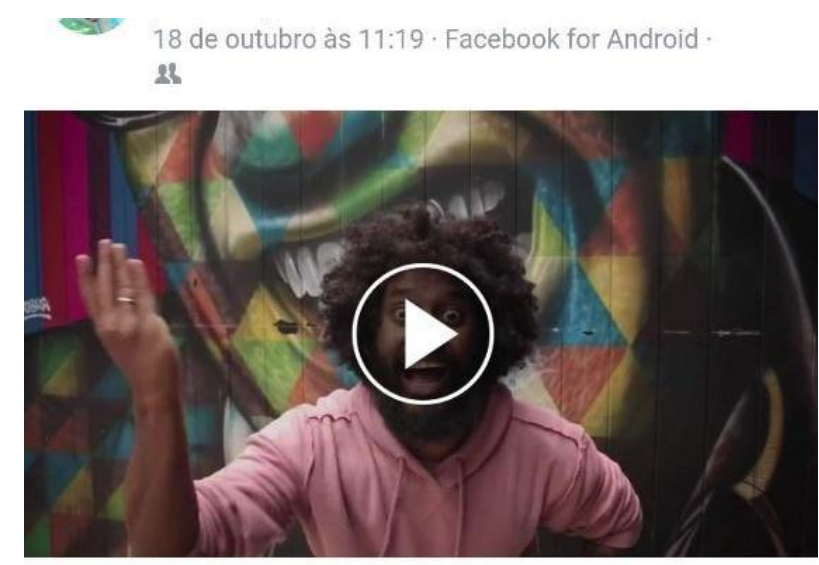

Edinho Poesia 16 de outubro às 00:50
Sou surdo
Ninguém vai curar a língua sinais
Tenho identidade
Souuuu surdoooo

Figura 6: Enfrentamento

Fonte: Print screen elaborado pelo autor (2008)

Compreendi, nos textos lidos, nas observações do Instagram e Facebook, e nas interlocuções com as imagens, que os surdos são participantes de uma lógica cultural singular, que acessam o mundo por outros canais sensíveis, não como limitados, mas pulsantes, intensos, autônomos na produção de suas narrativas vivenciadas, construtores de saberes. Participantes de múltiplas redes de sentidos existenciais, movimentam-se por diversas posições, identidades, num emaranhado de teias de significações que dão sentido à vida. Skliar citado por Strobel (2015), relembra que:

Foram mais de cem anos de práticas enceguecidas pela tentativa de correção, normalização e pela violência institucional; instituições especiais que foram reguladas tanto pela caridade e pela beneficência, quanto pela cultura social vigente que requeria uma capacidade para controlar, separar e negar a existência da comunidade surda, da língua de sinais, das identidades surdas e das experiências visuais que determinam o conjunto de diferenças dos surdos em relação a qualquer outro grupo de sujeitos (SKLIAR APUD STROBEL, 2015, p. 90).

Os surdos vêm enfrentando o desafio de desconstruir práticas de correção, normalização, provocadas pelas perspectivas das narrativas colonizadoras ouvintistas, segregações, invisibilização, opressões que os marcaram historicamente e que os perseguem ainda hoje. Apesar dos avanços políticos ainda há um longo caminho de lutas 
pela desconstrução de visualidades estigmáticas, lógicas dominantes construídas e sustentadas por uma concepção patológica que os imputa a marca de deficientes.

Essa proposição emancipatória dos subalternos é fomentada nos escritos de Santos (2010), que nos instiga ao reconhecimento da diversidade epistemológica de saberes do mundo, o que ele chama de 'A ecologia de saberes'.

A partir desse conceito, alinho minhas reflexões e análises com o autor Boaventura de Sousa Santos (2010), quando denuncia a compreensão de uma epistemologia homogênea, neutra, hierárquica, e avigora a pluralidades de formas, texturas, cores, ritmos, vibrações de multiformes práticas e saberes intersubjetivos produzidos de forma heterogênea pelos povos e culturas excluídas das narrativas oficiais, subjugadas, marginalizadas, silenciadas por um pensamento abissal de soberania epistêmica colonialista.

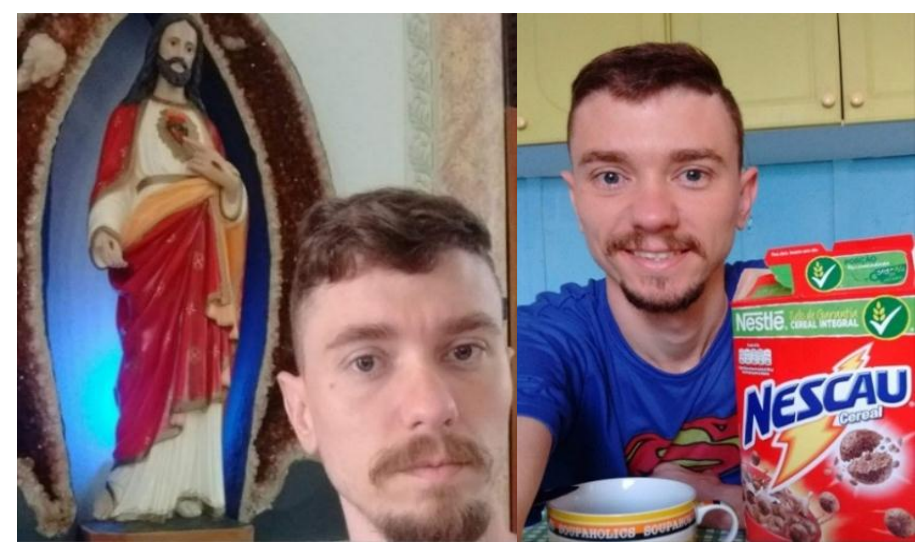

Figura 7: Trânsitos simbólicos

Fonte: Print screen elaborado pelo autor (2018)

Negar culturas, narrativas, visualidades e saberes autônomos de um povo que não se enquadra ao grupo predominante é imputá-los à marginalização social. Boaventura de Sousa Santos (2007) chama esse processo de 'epistemicídio', a morte do conhecimento dos povos dominados por uma ação concreta e cognitiva colonialista, capitalista, patriarcal, e neste caso, ouvintista (o ouvinte como modelo de normalidade humana, sendo o único capaz de produzir conhecimentos).

Foi embebido nessas provocações das Epistemologias do Sul que busquei observar e me envolver com os colaboradores da pesquisa e com o campo, a partir da possibilidade de interlocução com imagens, compreendendo que esta tem uma contribuição muito grande na construção de saberes, não apenas por suas funcionalidades figurativas, como 
suportes para a escrita, mas como potentes fontes para acessar realidades, usos de valor, trânsitos de socialidades. Esse entendimento é orientado por La Rocca (2014):

[...] a imagem é considerada como raiz de uma sensibilidade que caracteriza o domínio da sociologia visual e do imaginário, visando uma compreensão em profundidade das dimensões sociais do mundo através das extensões técnicas dos aparelhos de foto e vídeo (LA ROCCA, 2014, p. 283).

Por intermédio da extensão técnica do aparelho celular, encontrei caminhos para adentrar nas dimensões sociais da cultura surda a partir das imagens que possibilitaram aproximações com as diversidades de conhecimentos, saberes surdos, subjetividades. Nesta investigação, compreendi que as imagens são participantes ativas das relações sociais.

Diante dos trânsitos virtuais dos meus colaboradores, notei que as imagens amplificaram as suas ações comunicacionais, possibilitando uma maior inserção e participação na sociedade, potencializando ações de emancipação subjetiva/coletiva de uma lógica estigmatizante que tenta imputar ao surdo um silenciamento histórico, ou seja, o engessamento de suas possibilidades de existência, de suas identidades e de seus trânsitos vivenciais.

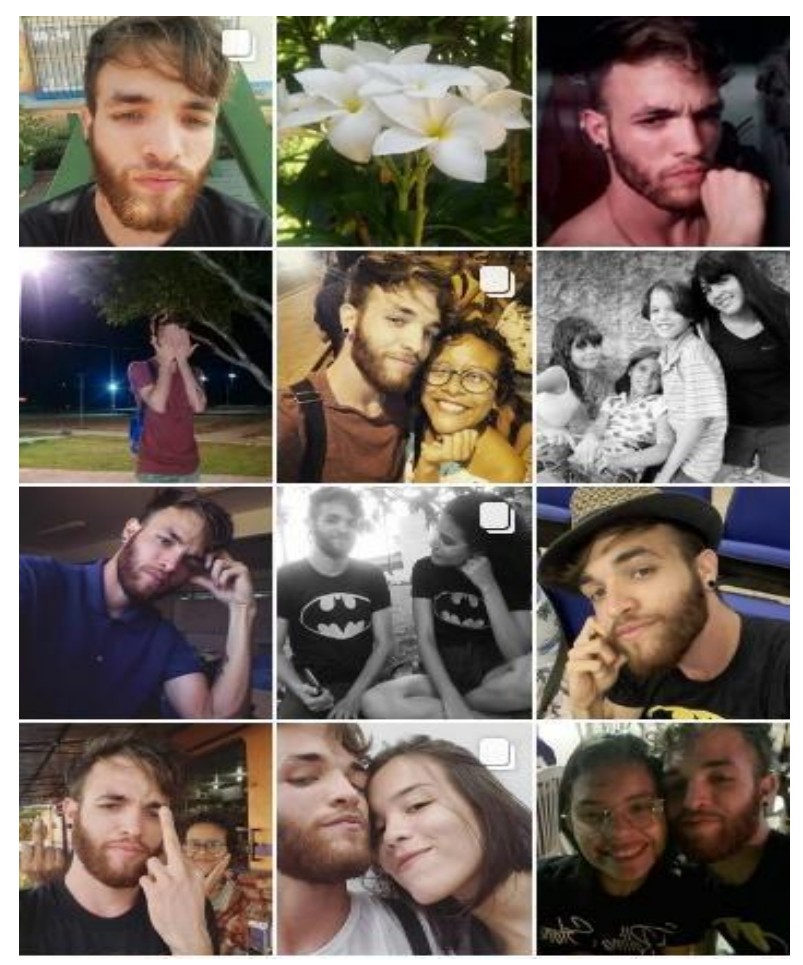

Figura 8: Narrativas existenciais 2

Fonte: Print screen elaborado pelo autor (2019) 
Durante todo o processo de pesquisa, a tentativa foi de perceber as indeterminações, aberturas, fragmentações de corpos que se moldam e se inventam no contato com o mundo por meio de múltiplas experiências visuais, de imagens fugazes que são projetadas nas redes sociais que abrem frestas por onde se podem observar processos de narrativas existenciais e invenção do ser, e que atuam como "um instrumento de captação e de restituição do teatro da vida quotidiana" (LA ROCCA, 2014, p. 116).

Diante das suas narrativas existenciais, compreendi que as identidades surdas se mostram pulsantes, fluidas, construídas nos entremeios de uma cultura singular, a cultura surda, mas que também se envolvem com as demais culturas que os cercam num movimento cambial intenso, potencializado pelas experiências visuais.

As linhas fronteiriças são transpassadas, os supostos guetos de socialidades passam a ser superados pelos trânsitos das imagens. Uma vez que tanto surdos como ouvintes estão fascinados, seduzidos pelas imagens que transpassam suas ações cotidianas, suas experiências com o mundo, e por meio delas constroem narrativas de si mesmos e dos outros.

Ressalto novamente que meus pensamentos e minhas interpretações não são pensamentos únicos e definidos e que os sentidos e significados produzidos por mim não foram neutros, pois foram baseados em minhas memórias, sentimentos, afetos, sensações, devaneios e temporalidades, como recorda Martins (2007), "os significados dependem de interpretações que se organizam e manifestam nos diálogos dos indivíduos com as imagens, objetos ou artefatos".

Os seres humanos e suas estruturas culturais são profundamente complexos. Assim, este trabalho não poderia dar conta de refletir sua totalidade. Devido a isso, desejo continuar mergulhando nas profundidades das intensidades dos corpos surdos, suas indeterminações identitárias, observando o constructo de suas narrativas existenciais, contrapontos das internalidades que são forjadas a partir de trânsitos simbólicos, acentuando suas singularidades e subjetividades.

\section{Referências}

BATAGLIN, M. Experiência visual e arte: elementos constituidores de subjetividades surdas. IX ANPED SUL - Seminário de Pesquisa em Educação da região sul, 2012. Disponível em: <http://www.ucs.br/etc/conferencias/index.php/anpedsul/ 9anpedsul/paper/viewFile/91/757>.Acesso em: 12 abr. 2016. 
CAMPOS, R. M. R. Ecos do silêncio: culturas e trajetórias de surdos em Macapá. 2016. 248f. - Tese (Doutorado) - Universidade Federal do Ceará, Programa de Pós-Graduação em Sociologia, Fortaleza (CE), 2016.

EIJI, H. Culturas surdas: o que se vê, o que se ouve. Dissertação - Universidade de Lisboa. Lisboa, 2012.

KOZINETS, R. V. Netnografia: realizando pesquisa etnográfica online. Tradução de Daniel Bueno. Porto Alegre: Penso, 2014.

LA ROCCA, F. A reprodutibilidade tecnológica da imagem. Tessituras, Pelotas, v. 2, n. 2, p. 114-128, jul./dez. 2014. Disponível em: <https://periodicos.ufpel.edu.br/ojs2/index.php/tessituras/article/view/4857/3920>. Acesso em: 26 jan. 2019.

MARTINS, R. A cultura visual e a construção social da arte, da imagem e das práticas do ver. In: OLIVEIRA, M. de O. (Org.). Arte, Educação e Cultura. Santa Maria: Ed. UFSM, 2007.

MARQUES. S. C. C. Imagem Fenômeno e diálogo Visual: conexões de pesquisa. Visagem, v. 3, n. 1, p. 85-109, 2017. Disponível em: <http://www.ppgcs.ufpa.br/revistavisagem/edicao_v3_n1/artigos/4_imagem_fenome_e_ dialogo/>. Acesso em 12 jan. 2019.

PERLIN, G. O ser e o estar sendo surdo: alteridade, diferença e identidade. Tese de Doutorado. Universidade Federal do Rio Grande do Sul, 2003.

SANTOS, B. de S. Para além do pensamento abissal: das linhas globais a uma ecologia de saberes. Novos Estudos. 2007

SANTOS, B. de S.; MENEZES, M. P. Epistemologias do Sul. Tradução e organização revisada por Margarida Gomes. São Paulo: Cortez Editora, 2010.

SAMAIN. E. As imagens não são bolas de sinuca: como pensam as imagens? In: SAMAIN E. (org.). Como pensam as imagens. Campinas: Ed. Unicamp, 2012.

As peles da fotografia: fenômeno, memória/arquivo, desejo. Visualidades, Goiânia, n. 1, v. 10, jan/jun. 2012. Disponível em: <www.revistas.ufg.br>. Acesso em: 20/01/2019.

SIBILIA, P. Redes ou paredes: a escola em tempos de dispersão. Rio de Janeiro. Contrapontos, 2012.

SILVA, C. M. da. Rastros das socialidades: Conversações com João Gilberto Noll e Luiz Ruffato. (Doutorado em Ciências Sociais) Programa de Pós - Graduação em Ciências Sociais. Universidade Estadual de Campinas, Campinas, 2009, 308.

SILVA, T. O que é, afinal, Estudos Culturais? Belo Horizonte. Autêntica, 2006.

STROBEL, K. As imagens do outro sobre a cultura surda. Florianópolis, Ed. Da UFSC, 2015. 
' Graduado em Licenciatura Plena em Artes Visuais - UNIFAP (2017) Especialista em Estudos Culturais e Políticas Públicas - UNIFAP (2019) Bacharel em Teologia - UNIGRAN (2020). Tem interesse por questões dos impactos das imagens nos processos de construção das subjetividades, identidades, culturas dos sujeitos surdos. Investigando através da Netnografia as interações e comunicações dos surdos através das imagens nos cyber espaços.

ii Doutora em Sociologia. Mestre em Cultura Visual pela Faculdade de Artes Visuais - FAVUFG. Especialista em arte Educação em Instituições Culturais. Professora das disciplinas na área de Ensino em arte da Universidade Federal do Amapá. Tem interesse por questões da visualidade e os impactos na aprendizagem dos sujeitos culturais na formação inicial de professores. Abordagem acerca das relações estéticas nos mundos da arte e poéticas nos processos culturais nas cidades. Tem experiência na área de processos de mediação com ênfase na formação de professores de artes visuais, atuando principalmente nos seguintes temas: Processos educativos em Arte, Poéticas Sociais, Feminismo, estéticas urbanas e cotidiano.

Como citar esse artigo:

LIMA, Welliton Quaresma; COSTA, Silvia Carla Marques. Mergulho netnográfico nas narrativas surdas: conversações com as imagens fenômenos. Revista Digital do LAV, Santa Maria: UFSM, v. 14, n. 1, p. 138-158, jan./abr. 2021. 